\title{
Estimation of nitrification capacity of rock media trickling filters in external nitrification BNR
}

\author{
AW Muller*, MC Wentzel and GA Ekama \\ Water Research Group, Department of Civil Engineering, University of Cape Town, Private Bag, Rondebosch 7701, South Africa
}

\begin{abstract}
In the external nitrification (EN) biological nutrient removal (BNR) activated sludge (AS) system, the nitrification process is removed from the BNR activated sludge system and performed 'externally' on an integrated nitrifying trickling filter (NTF). As such, optimum design and operation of the NTF is essential for reliable performance of the ENBNRAS system. Although information on the design and operation of NTFs is available in the literature, this experience is not directly applicable to the NTF in the ENBNRAS system. To address this deficiency, a full-scale ENBNRAS prototype was implemented at the Daspoort Wastewater Treatment Works (DWWTW) in Tshwane, South Africa. In this investigation an average apparent nitrification capacity of approximately 1.25 to $1.29 \mathrm{gN} \mathrm{per} \mathrm{m}^{2}$ of media surface area per day [gN/(ms $\left.\mathrm{s}^{2} \mathrm{~d}\right)$ ] ammonia removal was determined for 2 existing rock media TFs retrofitted as NTFs in the prototype ENBNRAS system (nominal surface area of $45 \mathrm{~ms}^{2} / \mathrm{m}^{3}$ for the rock media). This nitrification capacity corresponded to a removal efficiency of about $14 \mathrm{mgN} / \ell(96 \%)$, or $149 \mathrm{kgN} / \mathrm{d}$, of the influent ammonia load applied to the NTFs (average influent flow rate of $10 \mathrm{M} \ell / \mathrm{d}$ ). General concordance was found with corresponding nitrate and nitrite production and alkalinity usage measurements, which substantiated the observed removal performance. This paper details determination of the nitrification capacity of the 2 rock media NTFs used in the prototype ENBNRAS system.
\end{abstract}

Keywords: full-scale, activated sludge, BNR, nitrification, nitrifying trickling filter

\section{Introduction}

In the external nitrification (EN) biological nutrient removal (BNR) activated sludge (AS) system, the nitrification process is removed from the BNR activated sludge system and performed 'externally' on an integrated nitrifying trickling filter (NTF) system (Hu et al., 2000; 2003). As such, optimum design and operation of the NTF system is essential for reliable performance of the ENBNRAS system. Although information on the design and operation of NTFs is well established in the literature (Boller and Gujer, 1986; Lutz et al., 1990; Parker et al., 1989; 1995), this experience is limited to tertiary treatment applications. That is, as an upgrade of conventional wastewater treatment (e.g. activated sludge, aerated lagoon) systems to nitrify the treated effluents to meet ammonia discharge requirements (Lutz et al., 1990). Additionally, NTF design for tertiary treatment typically recommends plastic media, flooding capability for predator control, forced ventilation, continuous dosing and a well clarified secondary treated effluent as influent (Parker et al., 1989;1995). However, ENBNRAS implementation typically is intended as an upgrade or extension of existing facilities, in which case the NTF specifications are pre-existing (e.g. rock media, natural ventilation). Further, NTF performance as an integral unit process within ENBNRAS systems, particularly in combination with an upstream internal settling tank (IST), is lacking. Where such information has been developed, it has been within the area of research investigating the potential for anoxic P-uptake during denitrification (e.g. Wanner et al., 1992; Bortone et al., 1996; Kuba et al., 1996). The main advantage of anoxic P-uptake is purportedly in using the same substrate for

This paper was originally presented at the 2006 Water Institute of South Africa (WISA) Biennial Conference, Durban, South Africa, 21-25 May 2006.

* To whom all correspondence should be addressed.

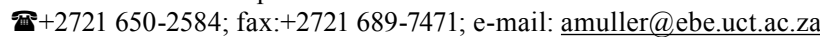

both BEPR and denitrification (but comes at a cost to BEPR, $\mathrm{Hu}$ et al., 2000). However, by focusing principally on anoxic P-uptake, this body of experience provides little and often inappropriate information regarding the performance dynamics of the attached growth NTF, the IST and the optimum operating and design guidelines for the integrated IST-NTF unit process in full-scale ENBNRAS implementation - all of which are essential for accurate characterisation and overall optimisation of the ENBNRAS system. Particularly lacking is appropriate estimation of the nitrification capacity of the NTFs in the ENBNRAS configuration, which is necessary for optimal specification of the NTFs, related flow streams and process loading rates. To remedy this deficiency, in collaboration between the City of Tshwane and University of Cape Town, a full-scale prototype ENBNRAS system was implemented at the Daspoort Wastewater Treatment Works (DWWTW) in Tshwane, South Africa, in 2003 (Muller et al., 2004). This paper describes determination of the nitrification capacity of the rock media NTFs used in this implementation.

\section{Overview of ENBNR implementation at Daspoort WWTW}

Detailed descriptions of the design and implementation of the prototype ENBNRAS system at Daspoort WWTW (DWWTW) are contained in Muller et al. (2004). In brief, DWWTW is located in downtown Pretoria and draws influent wastewater from a main collector sewer at an approximately constant rate. The raw wastewater undergoes screening, grit removal and primary sedimentation in Dortmund-type primary settling tanks (PSTs). The main treatment facilities available for the ENBNRAS implementation are listed in Table 1.

The general design approach was to integrate the trickling filters (TFs) of Modules 5-6 with the BNRAS system in Module 9 in the ENBNRAS configuration (Hu et al., 2000). Modules 


\begin{tabular}{|l|l|l|l|l|}
\hline \multicolumn{7}{|c|}{ SABLE 1 } \\
\hline Module & Location in plant & Type of unit process (Number) & Constructed, upgraded & Cap. (Me/d) \\
\hline $1-4$ & Eastern Works & Single bed rock media trickling filters (16) & $1913-1920$ & 9 \\
\hline $5-6$ & Eastern Works & Dual bed rock media trickling filters (4) & 1945,1995 & 9 \\
\hline $9-11$ & Western Works & 3-Stage Bardenpho activated sludge (3) & 1975,1988 & 40 \\
\hline
\end{tabular}

9, 10 and 11 are three parallel BNRAS systems each comprising a series of $9 \times 750 \mathrm{~m}^{3}$ compartments, for a total process volume of $6750 \mathrm{~m}^{3}$ per module. Modules 5 and 6 each comprise a pair of dual bed rock media (specific surface area of $\left.45 \mathrm{~m}_{\mathrm{s}}^{2} / \mathrm{m}^{3}\right)^{*}$ TFs of $21.6 \mathrm{~m}$ diameter $\times 3.7 \mathrm{~m}$ height, with 1 $284 \mathrm{~m}^{3}$ of media per TF (Table 2). [*To distinguish between a ' $m^{2}$ ' of cross-sectional (or 'plan') area, e.g. as usually used to quantify applied hydraulic loadings, and a ' $\mathrm{m}^{2}$ ' of media specific surface area, e.g. in expressing substrate loading or removal rates, a subscript 's' is used to define ' $m s^{2}$ ' for the latter; i.e. for reference to the media specific surface area $\left(A_{m}\right)$.] In the prototype ENBNR system, the 9 AS compartments of Module 9 were modified as follows (Fig. 1): Compartment 1 partitioned into pre-anoxic and anaerobic (1/3 and 2/3 respectively) zones, Compartments 2 to 3 anaerobic, Compartments 4 to 6 primary anoxic and Compartments 7 to 9 aerobic, with Compartment 7 to be switched to primary anoxic later on in the operation. For the required internal settling tanks (ISTs) between the anaerobic and anoxic reactors, 4 of the 6 Dortmund PSTs serving Modules 9 to 11 were modified for use as ISTs while the remaining 2 were retained for primary settling, to provide a common settled sewage to parallel Modules 9 to 11. A summary of the selected design criteria for ENBNR implementation at Daspoort is listed in Table 2. A process diagram of the implemented system is in Fig. 2, which shows newly installed pumps (P1 to P7) and existing a-recycle (P8) and RAS (P9) pumps in the system.

The ENBNRAS prototype system was started-up on $18^{\text {th }}$ August 2003. Operational implementation generally followed a conservative 3-Phased strategy, summarised in Table 2. Numerous process disruptions occurred during startup, which required various operational interventions to safeguard overall plant performance. Additionally, several operational modifications were implemented to effect the necessary process conditions of the start-up strategy, including utilisation of only the Module 5 TFs (in parallel), 3 x ISTs and $1 \mathrm{x}$ secondary settling tank (SST). Furthermore, dedicated operational routines and procedures were implemented to develop more detailed process information on the system. The increased monitoring highlighted:

- Ineffective isolation of the anaerobic (AN) reactor

- Accurate flow balancing and pump capacities for optimum process loadings

- The flexibility to balance NTF ammonia loading and wetting rate requirements, as particular problems negatively impacting full optimisation of NTF performance. These issues and related NTF performances are described below.

\section{Operational factors affecting NTF performance}

For a comprehensive description of the main operating conditions and full-scale performance of the ENBNR activated sludge system, see Muller et al. $(2005 ; 2006)$. The aspects specific to operation and performance of the NTFs, and, hence, determination of the maximum nitrification capacity in the Daspoort ENBNR system, are presented here.

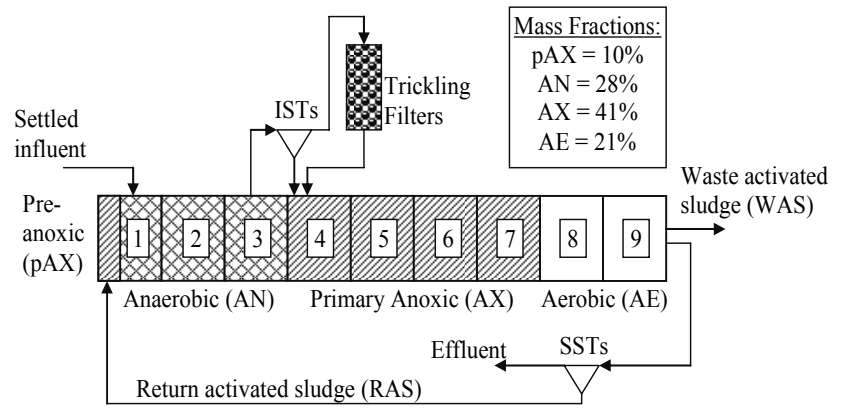

Figure 1

Design configuration of the prototype ENBNR activated sludge system at Daspoort Wastewater Treatment Works, shown with Compartment 7 anoxic

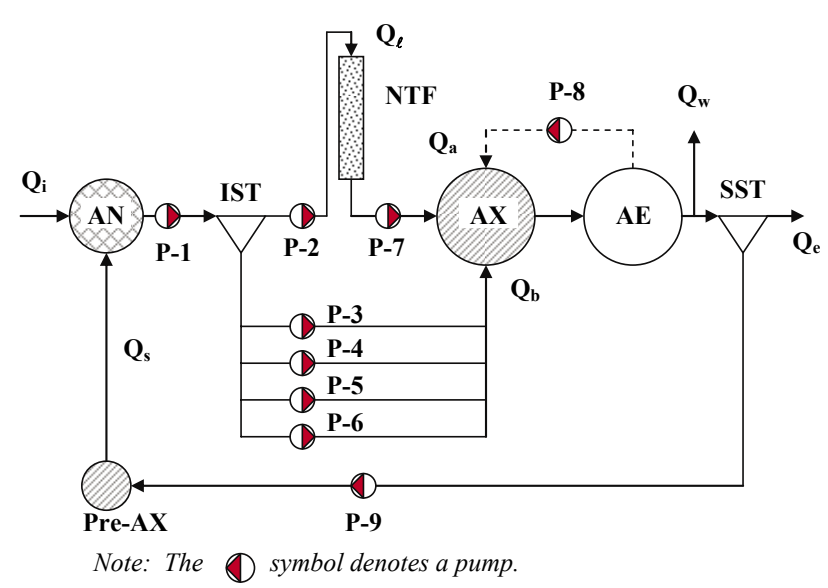

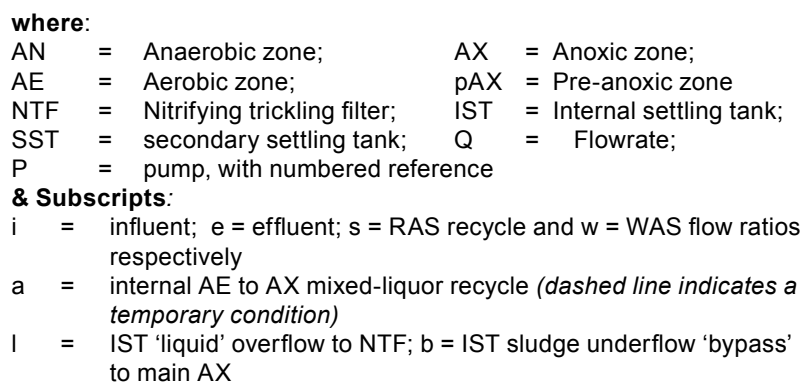

Figure 2

Process flow diagram of the prototype external nitrification (EN) BNRAS system implemented at Daspoort Wastewater Treatment Works (Muller et al., 2004)

\section{Ineffective isolation of the anaerobic reactor}

Effective isolation of the anaerobic (AN) zone is a fundamental requirement for EN, without which an excessive amount of influent free and saline ammonia (FSA) will bypass the mixed-liquor (ML) withdrawal point in the AN zone (for transfer to the ISTs, see Fig. 1). Hence, this FSA will bypass the NTFs and need to be nitrified in the AS system (as in a conventional BNRAS 


\begin{tabular}{|c|c|c|c|}
\hline \multicolumn{4}{|c|}{$\begin{array}{c}\text { TABLE } 2 \\
\begin{array}{c}\text { Design criteria (basis: January } 2000-\text { April 2002) selected for full-scale implementation of } \\
\text { external nitrification BNRAS at Daspoort WWTW (*Assumed value) }\end{array}\end{array}$} \\
\hline Settled Sewage Influent Characteristics & Symbol & Value & Unit \\
\hline Influent flow rate & $\mathrm{Q}_{\mathrm{i}}$ & 10 & $\mathrm{M} \ell / \mathrm{d}$ \\
\hline COD concentration & $\mathrm{S}_{\mathrm{ti}}$ & 320 & $\mathrm{mgCOD} / \ell$ \\
\hline Unbiodegradable particulate (and soluble) fraction & $\mathrm{f}_{\text {up }}\left(\mathrm{f}_{\text {us }}\right)$ & $0.04 *\left(0.10^{*}\right)$ & $\mathrm{COD} / \mathrm{COD}$ \\
\hline TKN concentration (ammonia concentration) & $\mathrm{N}_{\mathrm{ti}}\left(\mathrm{N}_{\mathrm{ai}}\right)$ & $35.8(19.5)$ & $\mathrm{mgN} / \ell$ \\
\hline \multicolumn{4}{|l|}{ Nitrifying Trickling Filters (Dual bed, Rock-media Type) } \\
\hline Number available (per Module) & & $4(2)$ & \\
\hline Nominal volume per TF (net volume of media per TF, $\mathrm{V}_{\mathrm{ms}}{ }^{[1]}$ & & $1928(1284)^{[1]}$ & $\mathrm{m}^{3}$ \\
\hline Rated media specific surface area $\left(\mathrm{A}_{\mathrm{ms}}\right)$ & & 45 & $\mathrm{~m}_{\mathrm{s}}^{2} / \mathrm{m}^{3}$ \\
\hline Total (net) media surface area per TF (per Module) ${ }^{[1]}$ & & $57780(115560)^{[1]}$ & $\mathrm{m}_{\mathrm{s}}^{2}$ \\
\hline Nominal nitrification capacity ( $\Rightarrow$ max allowable $N$ loading) & & $1^{*}$ & $\mathrm{gN} /\left(\mathrm{m}_{\mathrm{s}}^{2} \cdot \mathrm{d}\right)$ \\
\hline \multicolumn{4}{|l|}{ Activated Sludge System: } \\
\hline Sludge age & $\mathrm{R}_{\mathrm{s}}$ & 11 & $\mathrm{~d}$ \\
\hline MLSS concentration & $X_{t}$ & 2.5 & $\mathrm{gTSS} / \ell$ \\
\hline MLVSS/MLSS ratio & $\mathrm{f}_{\mathrm{i}}$ & 0.85 & VSS/TSS \\
\hline Dilute sludge volume index & DSVI & 140 & $\mathrm{~m} \ell / \mathrm{g}$ \\
\hline RAS recycle ratio (s) & $\mathrm{s}$ & 0.5 & s:1 w.r.t. $Q_{i}$ \\
\hline System aeration capacity (Compartments $8+9)$ & & $2 \times 45$ & $\mathrm{~kW}$ \\
\hline \multicolumn{4}{|c|}{ Start-up criteria Phase I: $\mathrm{Qi}=5 \mathrm{M} \ell / \mathrm{d} ; \mathrm{s}=0.5: 1 ; \mathrm{R}_{\mathrm{s}}=15 \mathrm{~d} ;$ a-recycle $=$ yes; Basin $7=\mathrm{AE}$} \\
\hline \multicolumn{4}{|c|}{ Start-up criteria Phase II: $\mathrm{Qi}=10 \mathrm{M \ell} / \mathrm{d} ; \mathrm{s}=0.5: 1 ; \mathrm{R}_{\mathrm{s}}=10 \mathrm{~d} ;$ a-recycle $=$ no; Basin $7=\mathrm{AX}$} \\
\hline \multicolumn{4}{|c|}{ 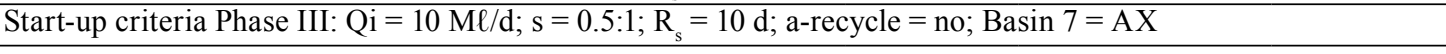 } \\
\hline
\end{tabular}

Note: [1] Each TF has a centre well $\approx 4.6 \mathrm{~m}$ in diameter $\Rightarrow$ the net media cross-sectional area $\left(\mathrm{A}_{\mathrm{cs}}\right)$ of each $\mathrm{TF}=347 \mathrm{~m}^{2}$; $\therefore$ the net media volume $=1284 \mathrm{~m}^{3}$ and net media surface area $=45 * 1284=57780 \mathrm{~m}_{\mathrm{s}}^{2}$ per TF.

system). Apparent dilution of the influent FSA had been consistently observed in the AN reactor due to back-flow from the main anoxic (AX) reactor (and indirectly from the aerobic reactor due to the a-recycle) to the AN reactor, mainly through a pre-existing overflow scum-slot connecting Compartmlents 3 and 4 of Module 9 (see Fig. 1). This resulted in improper loading of the NTFs via the clarified supernatant from the ISTs, which was confirmed by flow balances and comparison of series-samples of FSA along the process stream through the AN reactors. Substantially increased influent flow conditions (from 5.5 to $8.5 \mathrm{M} \ell / \mathrm{d})$, removal of the a-recycle and structural modifications were subsequently implemented in April to May 2004 to inhibit back-mixing of AX ML from entering the AN reactor. The influent flow was increased further to the design target of $10 \mathrm{M} \ell / \mathrm{d}$ (on 26/7/04), which acted as an additional hydraulic barrier. Follow-up series-sampling confirmed effective isolation of the AN reactor, with FSA concentrations in the IST overflow of about $22 \mathrm{mgN} / \ell$ (27/7 to 19/10/04) on average. It should be noted however, that this issue is site-specific to the DWWTW system and is unlikely to be encountered in general application of the ENBNR system at other sites.

\section{Flexibility to optimally balance NTF ammonia load with wetting rate}

An essential requirement for optimum nitrification performance in the NTFs is correct balancing of the applied ammonia load and media wetting rate (Parker et al., 1989; 1995). In particular, if the ammonia loading is too low then the nitrify growth will be reduced, which will result in uneven distribution of the nitrifiers in the media bed and unreliable nitrification performance. Alternatively, a too high ammonia load may result in exceeding the nitrification capacity of the NTF, giving rise to high ammo- nia in the NTF effluent. Furthermore, with a too-low media wetting rate, hydraulic short-circuiting will occur in the media bed resulting in the formation of dry-spots and 'patchy' biofilm development, which will promote the proliferation of biofilm predators ('grazers') and unreliable nitrification performance, respectively, to the detriment and potential loss of nitrification in the NTF. In contrast, a too high wetting rate may flood the void spaces in the media bed resulting in 'ponding' of the excess water on the surface of the NTF (a common occurrence with rock media TFs, e.g. Biddle and Wheatley, 1992), which will restrict efficient aeration and oxygen transfer through the media, also detrimental to optimum nitrification performance.

Accordingly, the focus of NTF operation had been initially on maximising the influent loading conditions applied to the NTFs, principally through maximisation of the FSA concentration and flow rate applied to the NTFs. In particular, the number of NTFs in operation was maintained at 2 (only Module 5) despite progressively increasing the settled influent wastewater load to the ENBNR system, i.e. from 5 to 8.5 to $10 \mathrm{Ml} / \mathrm{d}$ between April to October 2004 (see above). As a result of these loading increases, the average nitrification performance from April to October exhibited maximum ammonia removal rates (subject to inhibition by unintentional biodegradable COD loads due to IST failures) of approximately 0.98 to $1.25 \mathrm{gN} /\left(\mathrm{m}_{\mathrm{s}}{ }^{2} \cdot \mathrm{d}\right)(\sim 68-83 \%)$, which was comparable to optimum performance by purposedesigned plastic media tertiary treatment NTFs (approximately 0.85-1.5 gN/( $\left.\mathrm{m}_{\mathrm{s}}^{2} \cdot \mathrm{d}\right)$ on average, see Boller and Gujer, 1986; Lutz et al., 1990; Parker et al., 1989; 1995). However, despite this high removal, a maximum 'plateau' did not become evident (Fig. 3, 2004) during this operation (despite relatively consistent influent FSA levels), which indicated relative instability in the performance of the NTFs. Furthermore, the corresponding removal efficiency of $\sim 68-83 \%$ meant that $\sim 17-32 \%$ of the applied FSA 


\begin{tabular}{|c|c|c|c|}
\hline \multicolumn{4}{|c|}{$\begin{array}{c}\text { TABLE } 3 \\
\begin{array}{c}\text { Summary of average nitrification performances by the rock media NTFs of Module } 5 \\
\text { from April to June and July to October } 2004\end{array}\end{array}$} \\
\hline \multirow[b]{2}{*}{ Parameter } & \multicolumn{3}{|c|}{ Module 5 NTF Loading and Performance } \\
\hline & Jul - Oct 2004 & Apr - Jun 2004 & Units \\
\hline Applied influent flowrate, $\mathrm{Q}_{\mathrm{P} 2}$ & 9.12 & 9.55 & $\mathrm{M} \ell / \mathrm{d}$ \\
\hline Influent FSA concentration, $\mathrm{N}_{\text {ai, NTF }}$ & 18.3 & 17.2 & $\mathrm{mgN} / \ell$ \\
\hline Effluent FSA concentration, $\mathrm{N}_{\mathrm{ac}, \mathrm{NTF}}$ & 5.85 & 2.37 & $\mathrm{mgN} / \ell$ \\
\hline FSA removed, $\Delta \mathrm{N}_{\mathrm{a}, \text { nitrified }}$ & 12.45 & 14.8 & $\mathrm{mgN} / \ell$ \\
\hline FSA mass loading rate ${ }^{[1]}$ & 167 & 164 & $\mathrm{kgN} / \mathrm{d}$ \\
\hline Mass FSA Nitrified (as a percentage) & $113.5(68.0)$ & $144.3(86.2)$ & $\mathrm{kgN} / \mathrm{d}(\%)$ \\
\hline Number of NTFs in operation & 2 & 2 & Quantity \\
\hline Hydraulic loading rate ${ }^{[1]}$ (per NTF) & $13.1(13.1)$ & $13.8(13.8)$ & $\mathrm{m}^{3} / \mathrm{m}^{2} \mathrm{~d}$ \\
\hline Surface specific loading rate ${ }^{[1]}$ (per NTF) & $1.44(0.72)$ & $1.42(0.71)$ & $\mathrm{gN} /\left(\mathrm{m}_{\mathrm{s}}^{2} \cdot \mathrm{d}\right)$ \\
\hline Surface specific nitrification rate ${ }^{[1]}$ (per NTF) & $0.98(0.49)$ & $1.25(0.63)$ & $\mathrm{gN} /\left(\mathrm{m}_{\mathrm{s}}^{2} \cdot \mathrm{d}\right)$ \\
\hline
\end{tabular}

Note: [1] Based on a net cross-sectional area (A $A_{c s}$ of $347 \mathrm{~m}^{2}$ per NTF and a nominal media specific surface area $\left(\mathrm{A}_{\mathrm{ms}}\right)$ of $45 \mathrm{~m}_{\mathrm{s}}{ }^{2} / \mathrm{m}^{3}$ for the rock media. This gives a net volume of $1284 \mathrm{~m}^{3}$ media in each NTF, for a total $\mathrm{A}_{\mathrm{ms}}\left(\mathrm{A}_{\mathrm{ms}, t}\right)$ of $115560 \mathrm{~m}_{\mathrm{s}}^{2}$ for the 2 NTFs (Table 2).

load was in excess of the NTFs' nitrification capacity and had to be nitrified in the AS system, adding to the influent bypass load already entering the system via the AN-AX scum-slot. Clearly, the NTFs' nitrification capacity would need to be fully optimised to minimise the ammonia load discharged back to the AS system with the NTF effluent, and thus reduce dependence on the AS system for supplemental nitrification. Therefore, it became necessary to consider optimisation of the NTF ammonia loading and wetting rate requirements independently of each other, and, thus, to optimise overall EN capacity in the NTFs. Hence, the process flexibility for operating the Module 5 trickling filters in series instead of in parallel was investigated and implemented in December 2004.

\section{Implementation of pump capacity upgrades and increased NTF loading rates}

Following the review of ENBNR operation in the first year (October 2003 to October 2004), essential recommendations to optimise the system flow balance and NTF loading rates for the design influent condition of $10 \mathrm{Ml} / \mathrm{d}$ were implemented in December 2004. Specifically, the flow capacities of pumps P1, P2 and P7 were upgraded and the two Module 5 NTFs ('5-East, $5 \mathrm{E}$ ' and '5-West, $5 \mathrm{~W}$ ' respectively) operated in series, with $5 \mathrm{E}$ and $5 \mathrm{~W}$ configured as primary and secondary NTFs respectively. In this way the design hydraulic load of $15 \mathrm{Ml} / \mathrm{d}$ (with RAS ratio $0.5: 1$ ) applied to the AN reactor was balanced by the system pumping configuration shown in Fig. 2. Additionally, with series configuration of the Module 5 NTFs, the wetting and ammonia loading rates were doubled on $5 \mathrm{E}$ (i.e. as primary NTF it received the full P2 discharge flow, $\sim 11 \mathrm{M} /$ d), while $5 \mathrm{~W}$ (as secondary NTF it received the effluent from $5 \mathrm{E}$ as influent) received double the wetting rate (same flow as the full P2 discharge) but with reduced ammonia loading. A review of the new system configuration in March 2005 indicated no bypass of mixed-liquor through the AN-AX scum-slot and nearly continuous rotation of the NTFs' distributor arms (i.e. maximum dosing frequency) with no ponding - i.e. the increased wetting rate was successfully achieved (Muller et al., 2005). Further, observations of predator prevalence in the NTFs indicated only small snails (i.e. no adults) and very lit- tle flies and worms present, in contrast to the previous parallel operation when predators were significant. Several operational problems did occur during this time, however, most notably the successive failure of ISTs 4 and 6 between 10 and 14 February 2005. These failures caused a sudden reduction in the available IST settling surface area (by half), which, together with eventual start-up of the repaired ISTs, resulted in significant ML solids (active biomass) in the IST effluent and subsequent loading on the NTFs, with detrimental impacts on reliable nitrification; highlighting the sensitivity of the NTFs to IST failure in the ENBNR system.

\section{Maximum nitrification efficiency in the rock media NTFs}

A detailed performance analysis of the Daspoort ENBNR prototype system is contained in Muller et al. (2006b). This Section presents the performance trends in nitrification efficiency and determination of the nitrification capacity of the 2 (retrofitted) rock media NTFs of Module 5 in the ENBNR configuration.

\section{Initial optimisation of NTF performance (April to October 2004)}

The initial nitrification performance exhibited by the rock media NTFs is illustrated graphically in Fig. 3 (April to October 2004) and analyzed in Table 3 . In this analysis, process parameters were evaluated within the data set $95 \%$ confidence interval, with values lying outside this interval $(\approx$ mean $\pm 1.96 *$ sample standard deviation) rejected as outliers. The abbreviations AVG, SSD and $\mathrm{N}$ refer to average, sample standard deviation and number of data, respectively.

The ammonia removal trend for 2003 to 2004 in Fig. 3 shows that although a high ammonia removal efficiency ( 95\%) was attained in the period prior to the April flow increases (i.e. before 21/4/04), the influent ammonia concentration at that time was very low, around $6 \mathrm{mgN} / \ell$. Together with an average discharge rate of $6.77 \mathrm{M} \ell / \mathrm{d}$ measured for P2 (see Fig. 2) at the time, this gave very low mass removal rates for NTF operation from January to March 2004; about $0.33 \mathrm{gN} /\left(\mathrm{m}_{\mathrm{s}}^{2} \cdot \mathrm{d}\right)$ on an 
average apparent ${ }^{\#}$ media specific surface area basis (corresponding hydraulic loading rate $\sim 9.76 \mathrm{~m}^{3}$ / $\left.\mathrm{m}^{2} \cdot \mathrm{d}\right)$. [ [ Refers to a nitrification rate based on the difference between influent and effluent ammonia concentrations over the entire height of the NTF tower, as opposed to that derived from nitrification profiles taken at intervals down the tower height. That $i s$, in the 'apparent' rate estimation, the ammonia concentration in the effluent may already have been achieved higher up in the media bed, yet the volume of media surface assigned to that nitrification, i.e. used in the calculation, is for the entire tower volume]. With the increased settled influent flow rate implemented on 21/4/04 (from $\sim 5$ to $8.5 \mathrm{Ml} / \mathrm{d}$ ), the influent ammonia concentration applied to the NTFs increased correspondingly, to approximately $16 \mathrm{mgN} / \ell$. In response, the trend in nitrification efficiency exhibited a slight decline, presumably due to a low inventory of nitrifiers initially present, from about 95 to $85 \%$ over April to June 2004.

The performance analyses in Table 3 indicate that an average of approximately $68 \%$ of the influent FSA to Module 5 was nitrified between July and October 2004, for operation at an average applied ammonia loading rate (ALR) of 1.44 $\mathrm{gN} /\left(\mathrm{m}_{\mathrm{s}}^{2} \cdot \mathrm{d}\right)$ andanaverageappliedhydraulicloadingrate(HLR) of $13.1 \mathrm{~m}^{3} /\left(\mathrm{m}^{2} \cdot \mathrm{d}\right)$. This removal performance translates into $113.5 \mathrm{kgN} / \mathrm{d}$ fortheaverageinfluentflow-rateofapproximately 9.1 M $/ \mathrm{d}$, which gives an average apparent surface specific ammonia removal rate of about $0.98 \mathrm{gN} /\left(\mathrm{m}_{\mathrm{s}}^{2} \cdot \mathrm{d}\right)$ for the 2 rock media NTFs. By comparison, this performance was noticeably lower ( $22 \%$ ) than that previously observed from April to June (Table 3), even though the applied loading to the NTFs remained relatively consistent (ALR $\sim 1.4 \mathrm{gN} /\left(\mathrm{m}_{\mathrm{s}}^{2} \cdot \mathrm{d}\right.$ ), HLR $\sim 14 \mathrm{~m}^{3} /\left(\mathrm{m}^{2} \cdot \mathrm{d}\right)$ ). In particular, the average apparent surface specific nitrification rate had decreased from about 1.25 $\mathrm{gN} /\left(\mathrm{m}_{\mathrm{s}}^{2} \cdot \mathrm{d}\right)$ in April-June to $0.98 \mathrm{gN} /\left(\mathrm{m}_{\mathrm{s}}^{2} \cdot \mathrm{d}\right)$ in July-October. However, despite being noticeably lower than before, the apparent nitrification performance in July-October was practically equal to the nitrification capacity of $1 \mathrm{gN} /\left(\mathrm{m}_{\mathrm{s}}^{2} \cdot \mathrm{d}\right)$ assumed in the original design evaluation (Table 2), and within the range of optimum performances observed with plastic media NTFs in tertiary treatment $\left(0.85-1.5 \mathrm{gN} /\left(\mathrm{m}_{\mathrm{s}}^{2} \cdot \mathrm{d}\right)\right.$, see above). That is, the improved nitrification performance exhibited by the NTFs from April to October 2004 $\left(\approx 0.98-1.25 \mathrm{gN} /\left(\mathrm{m}_{\mathrm{s}}^{2} \cdot \mathrm{d}\right)\right) \quad$ validated the increased ALR achieved on the NTFs with the operational modifications implemented in April and July.

\section{Maximised (external) nitrification performance (January to June 2005)}

The effect of series operation of the Module 5 NTFs and the upgraded P1-P2-P7 pump capacities (implemented on 22 December 2004) on maximum nitrification performance by the NTFs, is assessed for the 6-month operating period from January to June 2005 in Fig. 3 and Tables 4 to 5 below. In Fig. 3, the ammonia removal trend indicates a significant improvement in the period from January to June 2005 (as compared to July to October 2004) due to the increased hydraulic and FSA loading rates applied to the NTFs with the series configuration. In particular, the FSA removal efficiency varied between 85 to $100 \%$ throughout the 6-month period and, despite deterioration due to successive IST failures in February to March 2005, was generally $>94 \%$. The results in Tables 4 and 5 indicate that an average of approximately $14 \mathrm{mgN} / \ell$ of the influent FSA to Module 5 was nitrified between January-June 2005. This translates into a nitrification efficiency of roughly $96 \%$ or, equivalently, about $149 \mathrm{kgN} / \mathrm{d}$ for the average influent flow of approximately 10.6 $\mathrm{M} \ell / \mathrm{d}$ discharged to Module 5. Overall, this gives an average apparent surface specific nitrification rate of about $1.29 \mathrm{gN} /\left(\mathrm{m}_{\mathrm{s}}^{2} \cdot \mathrm{d}\right)$ for the 2 rock media NTFs, which compares well with the average optimum performances attained by plastic media NTFs in tertiary treatment applications (i.e. $0.85-1.5 \mathrm{gN} /\left(\mathrm{m}_{\mathrm{s}}{ }^{2} \cdot \mathrm{d}\right)$ ).

\section{TABLE 4a}

NTF influent characteristics for the period 19 January to 30 June 2005

\begin{tabular}{|l|c|c|c|c|c|}
\hline Symbol & Units & AVG & SSD & N & Data Period/Ref. \\
\hline $\mathrm{pH}$ & - & 6.89 & 0.141 & 65 & $19 / 01 / 05-30 / 06 / 05$ \\
\hline $\mathrm{T}$ & ${ }^{\circ} \mathrm{C}$ & 22.4 & 2.33 & 66 & $19 / 01 / 05-30 / 06 / 05$ \\
\hline $\mathrm{COD}$ & $\mathrm{mgCOD} / \ell$ & 88.6 & 40.2 & 64 & $19 / 01 / 05-30 / 06 / 05$ \\
\hline $\mathrm{TSS}$ & $\mathrm{mgTSS} / \ell$ & 31.7 & 32.2 & 65 & $19 / 01 / 05-30 / 06 / 05$ \\
\hline $\mathrm{TKN}$ & $\mathrm{mgN} / \ell$ & 19.1 & 3.6 & 64 & $19 / 01 / 05-30 / 06 / 05$ \\
\hline Alkalinity & $\mathrm{mg} / \ell$ as CaCO & 205.5 & 11.8 & 63 & $19 / 01 / 05-30 / 06 / 05$ \\
\hline FSA & $\mathrm{mgN} / \ell$ & 14.6 & 2.0 & 65 & $19 / 01 / 05-30 / 06 / 05$ \\
\hline
\end{tabular}




\begin{tabular}{|c|c|c|c|c|c|c|c|}
\hline NTF 5 Eas & ind West efflue & $\begin{array}{r}\mathrm{T} \\
\text { conce }\end{array}$ & $\begin{array}{l}\text { E 4b } \\
\text { ations }\end{array}$ & $19 \mathrm{~J}$ & ry to & June 2 & \\
\hline Parameter & Units & & East ( & & & West ( & \\
\hline & & AVG & SSD & $\mathbf{N}$ & AVG & SSD & $\mathbf{N}$ \\
\hline $\mathrm{pH}$ & - & 7.28 & 0.127 & 63 & 7.22 & 0.138 & 64 \\
\hline $\mathrm{T}$ & ${ }^{\circ} \mathrm{C}$ & 22.1 & 2.5 & 66 & 21.85 & 2.64 & 66 \\
\hline COD & $\mathrm{mgCOD} / \ell$ & 93.9 & 43.4 & 63 & 52.67 & 17.9 & 63 \\
\hline TSS & $\operatorname{mgTSS} / \ell$ & 39.3 & 25.2 & 63 & 16.7 & 9.1 & 61 \\
\hline TKN & $\mathrm{mgN} / \ell$ & 10.4 & 3.67 & 62 & 3.66 & 1.5 & 64 \\
\hline Alkalinity & $\mathrm{mg} / \ell$ as $\mathrm{CaCO}_{3}$ & 135.9 & 13.0 & 59 & 98.4 & 8.8 & 60 \\
\hline $\mathrm{NO}_{3}$ & $\mathrm{mgN} / \ell$ & 9.1 & 1.55 & 55 & 15.43 & 2.0 & 58 \\
\hline $\mathrm{NO}_{2}$ & $\mathrm{mgN} / \ell$ & 0.34 & 0.12 & 55 & 0.18 & 0.174 & 57 \\
\hline FSA & $\mathrm{mgN} / \ell$ & 5.73 & 1.86 & 62 & 0.58 & 0.515 & 66 \\
\hline Module 9 Effluent & Units & & & & AVG & SSD & $\mathbf{N}$ \\
\hline $\mathrm{NO}_{3}^{-}$ & $\mathrm{mgN} / \ell$ & - & - & - & 4.18 & 1.25 & 40 \\
\hline $\mathrm{NO}_{2}^{-}$ & $\mathrm{mgN} / \ell$ & - & - & - & 1.35 & 1.42 & 40 \\
\hline FSA & $\mathrm{mgN} / \ell$ & - & - & - & 0.25 & 0.36 & 41 \\
\hline
\end{tabular}

\begin{tabular}{|c|c|c|c|}
\hline \multicolumn{4}{|c|}{$\begin{array}{l}\text { TABLE } 5 \\
\text { Average loadings and performance parameters for series operation of the Module } 5 \text { NTFs } \\
\text { from January to June } 2005\end{array}$} \\
\hline \multirow[b]{2}{*}{ Parameter } & \multicolumn{3}{|c|}{$\begin{array}{l}\text { Loading and Performance Parameters for Module } 5 \text { in } \\
\text { Series }\end{array}$} \\
\hline & NTF 5-East (Lead) & NTF 5-West (Follow) & Units \\
\hline Applied influent flow rate $\left(\equiv \mathrm{Q}_{\mathrm{P} 2}\right)$ & 10.64 & $(10.64)$ & $\mathrm{M} \ell / \mathrm{d}$ \\
\hline Applied hydraulic loading rate ${ }^{[1]}$ & 30.66 & $(30.66)$ & $\mathrm{m}^{3} / \mathrm{m}^{2} \cdot \mathrm{d}$ \\
\hline Influent FSA concentration, $\mathrm{N}_{\mathrm{aiNTF}}$ & 14.6 & $(5.73)^{[2]}$ & $\mathrm{mgN} / \ell$ \\
\hline Effluent FSA concentration, $\mathrm{N}_{\mathrm{ae} N \mathrm{NTF}}$ & 5.73 & $0.58^{[3]}$ & $\mathrm{mgN} / \ell$ \\
\hline FSA removed, $\Delta \mathrm{N}_{\mathrm{a}, \text { nitrified }}$ & 8.87 & 5.15 & $\mathrm{mgN} / \ell$ \\
\hline Total influent FSA loading rate rI] $^{[I]}$ & $14.6 * 10.64=155.3$ & & $\mathrm{kgN} / \mathrm{d}$ \\
\hline$\Rightarrow$ overall mass loading rate & 1.34 & & $g N /\left(m_{s}^{2} \cdot d\right)$ \\
\hline Total (combined) FSA removed & $8.87+5.15=14.02$ & & $m g N / \ell$ \\
\hline Overall FSA removal rate (as a \%) & $10.64 * 14.02=149.17$ & $(96 \%)$ & $\mathrm{kgN} / \mathrm{d}$ \\
\hline Mass FSA nitrified (as a $\%$ of total removal) & $94.38(63.3)$ & \begin{tabular}{|r|}
$54.80(36.7)$ \\
\end{tabular} & $\mathrm{kgN} / \mathrm{d}(\%)$ \\
\hline FSA mass loading rate & 155.3 & 60.97 & $\mathrm{kgN} / \mathrm{d}$ \\
\hline Surface specific loading rate ${ }^{[1]}$ & 2.69 & 1.06 & $\mathrm{gN} /\left(\mathrm{m}_{\mathrm{s}}^{2} \cdot \mathrm{d}\right)$ \\
\hline Surface specific nitrification rate ${ }^{[1]}$ & 1.63 & 0.95 & $\mathrm{gN} /\left(\mathrm{m}_{\mathrm{s}}^{2} \cdot \mathrm{d}\right)$ \\
\hline
\end{tabular}

Note: [1] Based on a net cross-sectional area $\left(\mathrm{A}_{\mathrm{cs}}\right)$ of $347 \mathrm{~m}^{2}$ per NTF and a nominal media specific surface area $\left(\mathrm{A}_{\mathrm{ms}}\right)$ of $45 \mathrm{~m}_{\mathrm{s}}^{2} / \mathrm{m}^{3}$ for the rock media. This gives a net volume of $1284 \mathrm{~m}^{3}$ media in each NTF, for a total $\mathrm{A}_{\mathrm{ms}}\left(\mathrm{A}_{\mathrm{ms}, t}\right)$ of $115560 \mathrm{~m}_{\mathrm{s}}^{2}$ for the 2 NTFs (Table 2).

[2] In series operation, the influent to $5 \mathrm{~W}$ is the same as the effluent from $5 \mathrm{E}$.

[3] In series operation, the effluent from $5 \mathrm{~W}$ is the ultimate effluent from the NTF (EN) system discharged to the AS process.

The validity of this nitrification performance (Table 5) by the rock media NTFs is supported by the nearly constant trend in ammonia removal efficiency over the 6-month period (JanuaryJune 2005, Fig. 3), and the relatively little variation indicated by the small standard deviations in the sample data (Table 4). Accordingly, the January to June nitrification performance of $1.29 \mathrm{gN} /\left(\mathrm{m}_{\mathrm{s}}^{2} \cdot \mathrm{d}\right)$ indicates a reliable maximum rate, and therefore characterises the nitrification capacity of the Module 5 NTFs.

Comparing the media specific nitrification rate of 1.29 $\mathrm{gN} /\left(\mathrm{m}_{\mathrm{s}}^{2} \cdot \mathrm{d}\right)$ for January-June 2005 when the two NTFs were operated in series (Table 5) with the values of 0.98 to $1.25 \mathrm{gN} /\left(\mathrm{m}_{\mathrm{s}}^{2} \cdot \mathrm{d}\right.$ ) for April to October 2004 when the two NTFs were operated in parallel (Table 3 ), clearly series operation significantly enhanced NTF performance (overall FSA loading rates generally similar,
$1.3 \approx 1.4 \mathrm{gN} /\left(\mathrm{m}_{\mathrm{s}}^{2} \cdot \mathrm{d}\right)$ respectively). Further, visual inspections indicated that substantially fewer predatory organisms were present with series than with parallel operation, and that the flow distribution across the media was significantly improved. These changes can be ascribed directly to the increased wetting rates with series operation controlling predator proliferation and improving flow distribution, and are in agreement with observations in the literature, as noted above. Thus, changing the NTF operating mode from parallel to series operation provides the means to increase media wetting rates without changing the overall ammonia loading rate treated (Table 5, but ammonia loading rates to the individual NTFs are changed as noted above), resulting in significantly improved performance.

The assessment of maximised nitrification performance 
by the rock media NTFs from January to June 2005 is substantiated by the almost constant difference between the influent and effluent FSA trend lines in Fig. 3. In particular, as shown in Fig. 4, this relationship is especially evident in the relatively parallel trajectories of the influent and effluent FSA trends for NTF 5E (the lead NTF). In this plot, the 5E effluent FSA concentration trend generally matches the variation in the 5E influent FSA with an almost constant difference of 8 to $10 \mathrm{mgN} / \ell$, which is particularly noticeable in the period after 12 April when the effluent values exhibit consistent increase with the increase in influent FSA.

Therefore, on this basis, an average apparent nitrification capacity of approximately 1.25 to $1.29(\approx 1.27) \mathrm{gN} /\left(\mathrm{m}_{\mathrm{s}}^{2} \cdot \mathrm{d}\right)$ can be assessed for the 2 rock media NTFs of Module 5, which is comparable to optimum performances by tertiary treatment NTFs $\left(0.85\right.$ to $\left.1.5 \mathrm{gN} /\left(\mathrm{m}_{\mathrm{s}}{ }^{2} \cdot \mathrm{d}\right)\right)$, and close to the nominal value of $1 \mathrm{gN} /\left(\mathrm{m}_{\mathrm{s}}^{2} \cdot \mathrm{d}\right)$ assumed in the preliminary design evaluation (Table 2). It should be noted, however, that the applied HLR associated with the maximised performance of the series operated NTFs (Table 5) is significantly lower than the $72-96 \mathrm{~m}^{3} / \mathrm{m}^{2} \cdot \mathrm{d}$ recommended by Boller and Gujer (1986) for plastic media NTFs in tertiary treatment, and much less than the optimum $\approx 120 \mathrm{~m}^{3} / \mathrm{m}^{2} \cdot \mathrm{d}$ used in studies with 'biofilm controlled' (BC)NTFs by Parker et al. (1989, 1995). Yet, despite this inconsistency, the maximum nitrification rate of $\approx 1.27 \mathrm{gN} /\left(\mathrm{m}_{\mathrm{s}}^{2} \cdot \mathrm{d}\right)$ achieved with the rock media NTFs at Daspoort is comparable with the average optimal performances of 0.85 to $1.5 \mathrm{gN} /\left(\mathrm{m}_{\mathrm{s}}^{2} \cdot \mathrm{d}\right)$ achieved in these applications. Conversely, however, the ALRs of 1.1 and $2.7 \mathrm{gN} /\left(\mathrm{m}_{\mathrm{s}}^{2} \cdot \mathrm{d}\right)$ applied to the secondary and primary NTFs respectively during the (maximised) performance are consistent with applied ALRs of 1.24 to $2.45 \mathrm{gN} /\left(\mathrm{m}_{\mathrm{s}}{ }^{2} \cdot \mathrm{d}\right)$ associated with maximum performances by tertiary treatment NTFs (e.g. Duddles et al., 1974; Parker et al., 1995; 1997). Accordingly, this discrepancy of inconsistent HLR but consistent ALR conditions for optimised NTF performance in ENBNR vs. tertiary treatment applications emphasises that direct extrapolation of NTF experience in tertiary treatment to design and operation of the NTF (typically conventionally designed TFs retrofitted to serve as NTFs) in the ENBNR system should be approached with due care.

\section{Related external nitrification system perform- ances}

\section{Nitrate and nitrite production trends in (ultimate) NTF effluent}

For comparison, the $\mathrm{NO}_{3}^{-}$and $\mathrm{NO}_{2}^{-}$concentration trends in the effluent from Module 5 are presented together with the NTF influent FSA in Fig. 5. As expected, for the period of maximised nitrification performance (January to June 2005), the trend in effluent $\mathrm{NO}_{3}$ - closely matches the corresponding influent FSA supporting the near $100 \%$ nitrification efficiency observed in
Fig. 3 (corresponding $\mathrm{NO}_{2}^{-}$levels were negligible throughout). On average, about $15.6 \mathrm{mgN} / \ell \mathrm{NO}_{3}^{-}+\mathrm{NO}_{2}^{-}$(' $\mathrm{NO}_{\mathrm{x}}$ ') was formed between January to June, which is about $166 \mathrm{kgN} / \mathrm{d}$ for the average influent flow of $10.6 \mathrm{M} \ell / \mathrm{d}$ (Tables 4 to 5 ). This is a difference of $\sim 11 \%$ with respect to the average $149.2 \mathrm{kgN} / \mathrm{d}$ FSA removal estimated for the period, which indicates a reasonable $\mathrm{N}$ balance for the observed ammonia removal.

\section{Average observed alkalinity utilisation}

Additionally, the corresponding average alkalinity utilisation was approximately $107.1 \mathrm{mg} / \ell$ as $\mathrm{CaCO}_{3}$ (Table 4). Accepting that $7.1 \mathrm{mg} / \ell$ as $\mathrm{CaCO}_{3}$ alkalinity is utilised per $\mathrm{mgN} / \ell \mathrm{FSA}$ nitrified (WRC, 1984), this is equivalent to a theoretical nitrification performance of approximately $15.1 \mathrm{mgN} / \ell$ (or $160.5 \mathrm{kgN} / \mathrm{d}$ ) for the Module 5 NTFs. By comparison, this is only about $8 \%$ more than the average observed ammonia removal of $14 \mathrm{mgN} / \ell$ and about $3 \%$ less than the average observed $\mathrm{NO}_{\mathrm{x}}$ production of 15.6 $\mathrm{mgN} / \ell$. Therefore, together with the $11 \%$ difference between the average observed $\mathrm{NO}_{x}$ production and FSA nitrified, the comparison of average observed nitrification with alkalinity usage indicates a good balance for the process data of January to June 2005, which substantiates the maximum rate of 1.25-1.29 $(\approx 1.27) \mathrm{gN} /\left(\mathrm{m}_{\mathrm{s}}^{2} \cdot \mathrm{d}\right)$ estimated for the 2 rock media NTFs.

\section{Effect of influent COD loading on nitrification efficiency}

The average NTF influent COD and TSS concentrations during maximised nitrification performance (January to June 2005) are shown in Table 4. Overall, the difference between average influent and effluent COD values appear contradictory when examining periods of lowered (July to October 2004, Table 3) and optimal (January to June 2005, Table 5) nitrification performances. In particular, the average nitrification efficiency of $68 \%$ in July to October corresponded with NTF influent and effluent COD values of 98.7 and $94.8 \mathrm{mgCOD} / \ell$ respectively, indicating no apparent COD utilisation and hence suggestive of no apparent competitive heterotrophic activity in the NTFs that 


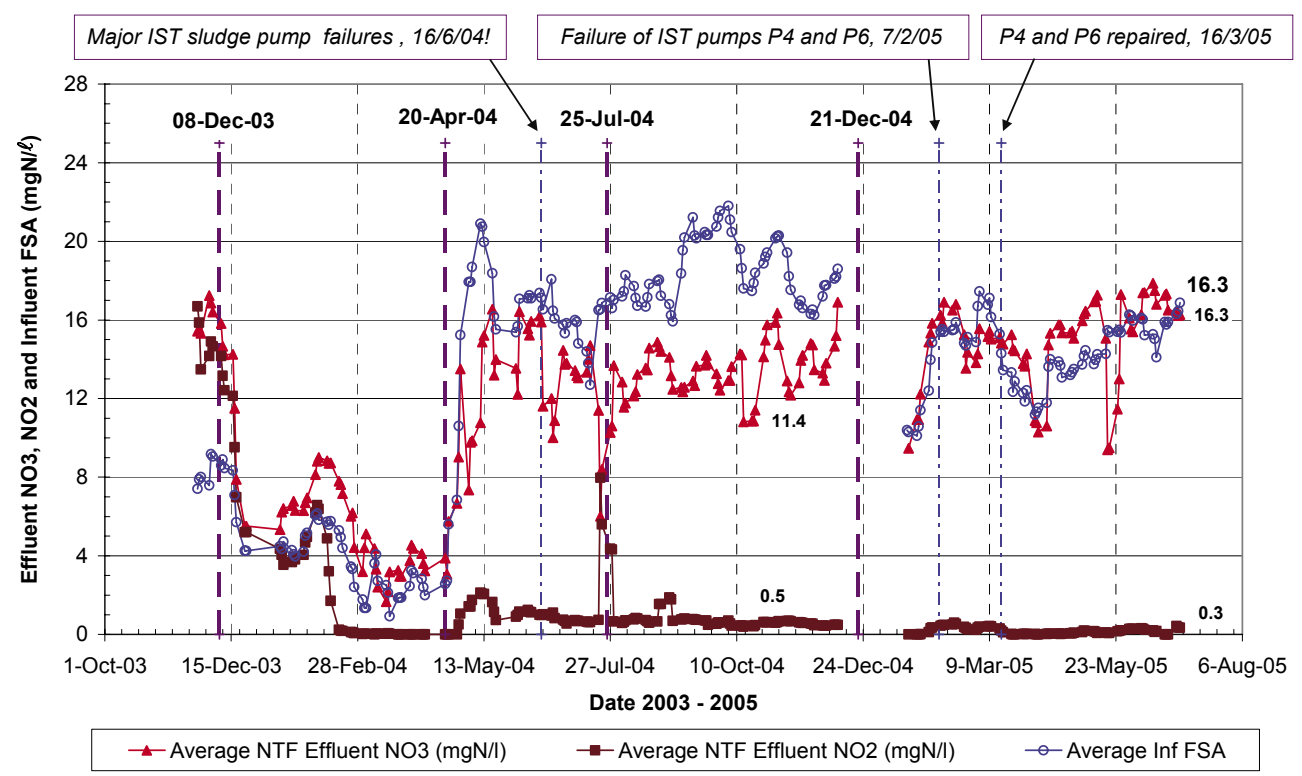

Figure 5

$\mathrm{NO}_{3}{ }^{-}$and $\mathrm{NO}_{2}{ }^{-}$concentration trends in the effluent from Module 5

\section{References}

BOLLER $\mathrm{M}$ and GUJER $\mathrm{W}$ (1986) Nitrification in tertiary trickling filters followed by deep-bed filters. Water Res. 20 (11) 1363-1373.

BORTONE G, SALTARELLI $\mathrm{R}$, ALONOSO V, SORM R, WANNER $\mathrm{J}$ and TICHE A (1996) Biological anoxic phosphorus removal - The Dephanox process. Water Sci. Technol. 34 (1-2).

HU ZHI-RONG, SÖTEMANN $S$, MOODLEY R, WENTZEL MC and EKAMA GA (2003) Experimental investigation of the external nitrification biological nutrient removal activated sludge (ENBNRAS) system. Biotech. and Bioeng. 83 (3) $260-273$

HU ZHI-RONG, WENTZEL MC and EKAMA GA (2001) External Nitrification in Biological Nutrient Removal Activated Sludge Systems.

would undermine the nitrifiers' efficiency (it was subsequently concluded that the lowered nitrification was mainly due to ineffective media wetting and consequent predator proliferation, Section 3). In contrast, the maximum nitrification efficiency in January-June, achieved with increased wetting and loading rates on the NTFs (hence suppressed predators and improved biofilm control, Parker et al., 1989), corresponded to an apparent COD utilisation of $35.9 \mathrm{mgCOD} / \ell(\sim 40 \%)$ in the NTFs (Table 4 ), yet near complete removal $(96 \%)$ of the influent ammonia was achieved. Thus, it would appear that the NTFs sustained some measure of heterotrophic activity (COD utilisation) while achieving near complete ammonia removal, and reduced efficiency although heterotrophic activity was negligible.

\section{Conclusion}

In conclusion, the ammonia removal performance in the rock media NTFs of the prototype ENBNR system indicated successful enhancement of nitrification efficiency following increased wetting rates applied to the NTFs (with additionally increased FSA loading applied to the lead NTF), by changing from parallel to series operation of the NTFs. This performance corresponded to a maximum removal efficiency of $14 \mathrm{mgN} / \ell(96 \%)$ of the applied influent FSA, or $149 \mathrm{kgN} / \mathrm{d}$ for the applied influent flow of $10 \mathrm{M \ell} / \mathrm{d}$, and translates into a media-specific nitrification capacity of approximately $1.29 \mathrm{gN} /\left(\mathrm{m}_{\mathrm{s}}^{2} \cdot \mathrm{d}\right.$ ) (compared to 0.98 $1.25 \mathrm{gN} /\left(\mathrm{m}_{\mathrm{s}}^{2} \cdot \mathrm{d}\right)$ in parallel operation). This maximum rate compared well with corresponding $\mathrm{NO}_{3}^{-}+\mathrm{NO}_{2}-$ production and alkalinity usage measurements, which substantiated the observed performance. Hence, an overall ammonia removal capacity of 1.25-1.29 $(\approx 1.27) \mathrm{gN} /\left(\mathrm{m}_{\mathrm{s}}^{2} \cdot \mathrm{d}\right)$ was assessed for the 2 rock media NTFs of the ENBNR prototype system at Daspoort WWTW.
Research Report W108, Department of Civil Engineering, University of Cape Town, Rondebosch 7701, South Africa.

HU ZHI-RONG, WENTZEL MC and EKAMA GA (2000) External nitrification in biological nutrient removal activated sludge systems. Water SA 26 (2) 225-238.

KUBA T, VAN LOOSDRECHT MCM and HEIJNEN JJ (1996) Phosphorus and nitrogen removal with minimal COD requirement by integration of nitrification in a two-sludge system. Water Res. 42 (1-2) 1702-1710.

LUTZ M.P, PRATT AM, PARKER DS and BRISCHKE KV (1990) Full-scale performance of nitrifying trickling filters. Proc. 63 $3^{\text {rd }}$ Annual Water Pollution Control Federation Conference, Washington DC, USA, October.

MULLER AW, WENTZEL MC, SAAYMAN G, ESTERHUYSE CM, PRINSLOO J, SNYMAN JS and EKAMA GA (2006) Two years operating experience of full-scale external nitrification BNR activated sludge. Proc. WISA Bienn. Conf.and Exhibition. Durban, South Africa, 21-25 May.

MULLER AW, SÖTEMANN SW, WENTZEL MC, EKAMA GA, SAAYMAN G, ESTERHUYSE CM, PRINSLOO J and SNYMAN JS (2005) Practical Implementation of External Nitrification in Biological Nutrient Removal Activated Sludge Systems. Draft Report April 2001 - December 2005 to the Water Research Commission, Contract No. K5/1262.

MULLER AW, WENTZEL MC, SAAYMAN GB, VAN DER MERWE SA, ESTERHUYSE CM, SNYMAN JS and EKAMA GA (2004) Full-scale implementation of external nitrification biological nutrient removal at the Daspoort Wastewater Treatment Works, Tshwane Metropolitan Municipality. Water SA WISA 2004 Special Edition 30 (5).

PARKER D, LUTZ M, ANDERSSON B AND ASPEGREN H (1995) Effect of operating variables on nitrification rates in trickling filters. J. WPCF 61 (5).

PARKER D, LUTZ M, DAHL R and BERNKOPF S (1989) Enhancing nitrification rates in nitrifying trickling filters through biofilm control. Water Env. Res. 67 (7).

WANNER J, CECH JS and KOS M (1992) New process design for biological nutrient removal. Water Sci. Technol. 25 (4-5) 445-448.

WRC (1984) Theory, Design and Operation of Nutrient Removal Activated Sludge Processes. Water Research Commission, Private Bag X03, Gezina 0031, RSA. 